\title{
Computational Design of a Krueger Flap Targeting Conventional Slat Aerodynamics
}

\author{
H. Dogus Akaydin*, \\ Science and Technology Corporation, NASA Ames Research Center, Moffett Field, CA \\ Jeffrey A. Housman ${ }^{*}$ Cetin C. Kiris ${ }^{\dagger}$, \\ NASA Ames Research Center, Moffett Field, CA \\ Christopher J. Bahr ${ }^{\ddagger}$ and Florence V. Hutcheson ${ }^{\S}$ \\ NASA Langley Research Center, Hampton, VA
}

\begin{abstract}
In this study, we demonstrate the design of a Krueger flap as a substitute for a conventional slat in a high-lift system. This notional design, with the objective of matching equivalent-mission performance on aircraft approach, was required for a comparative aeroacoustic study with computational and experimental components. We generated a family of high-lift systems with Krueger flaps based on a set of design parameters. Then, we evaluated the high-lift systems using steady 2D RANS simulations to find a good match for the conventional slat, based on total lift coefficients in free-air. Finally, we evaluated the mean aerodynamics of the high-lift systems with Krueger flap and conventional slat as they were installed in an open-jet wind tunnel flow. The surface pressures predicted with the simulations agreed well with experimental results.
\end{abstract}

\section{Introduction}

It is not clear why no one has tried to develop a folding, bull-nose Krueger flap that deploys to a shallower angle to provide a slot to make it perform more like a slat.

P. K. C. Rudolph, $1996^{1}$

A Krueger flap is a type of high-lift device that is deployed from the lower side of a wing around the leading edge. Also known as a "leading edge flap" or a "nose flap", a Krueger flap is typically cut out of the cruise-wing geometry without affecting the wing surfaces near and above the leading edge. Therefore, unlike a conventional slat, a Krueger flap is stowed and stored in the lower side of the wing, and hence it does not introduce surface discontinuities that cause early transition to turbulence on the top surface. ${ }^{1}$ A Krueger flap can shield the leading edge during take-off and landing against insect and debris contamination, ${ }^{2,3}$ which, at cruise, can also cause early transition to turbulence or clog boundary layer suction channels if a laminar flow control technology is used. ${ }^{4}$ Therefore, a Krueger flap is preferred when delay of transition to turbulence on the top surface of a wing is desired. ${ }^{5}$

The evolution of Krueger flaps is partially illustrated in Figure 1, starting with its original design introduced by W. Krueger in $1947 .{ }^{6}$ The concept was realized on several large aircrafts, chiefly by Boeing, and improved significantly over the years. In 1970, the Boeing 747 featured a Krueger flap with a four-bar link

\footnotetext{
* Research Scientist, Computational Aerosciences Branch, NAS Division

${ }^{\dagger}$ Branch Chief, Computational Aerosciences Branch, NAS Division, AIAA Senior Member

$\ddagger$ Research Engineer, Aeroacoustics Branch, AIAA Senior Member

$\S$ Senior Research Engineer, Aeroacoustics Branch, AIAA Senior Member
} 


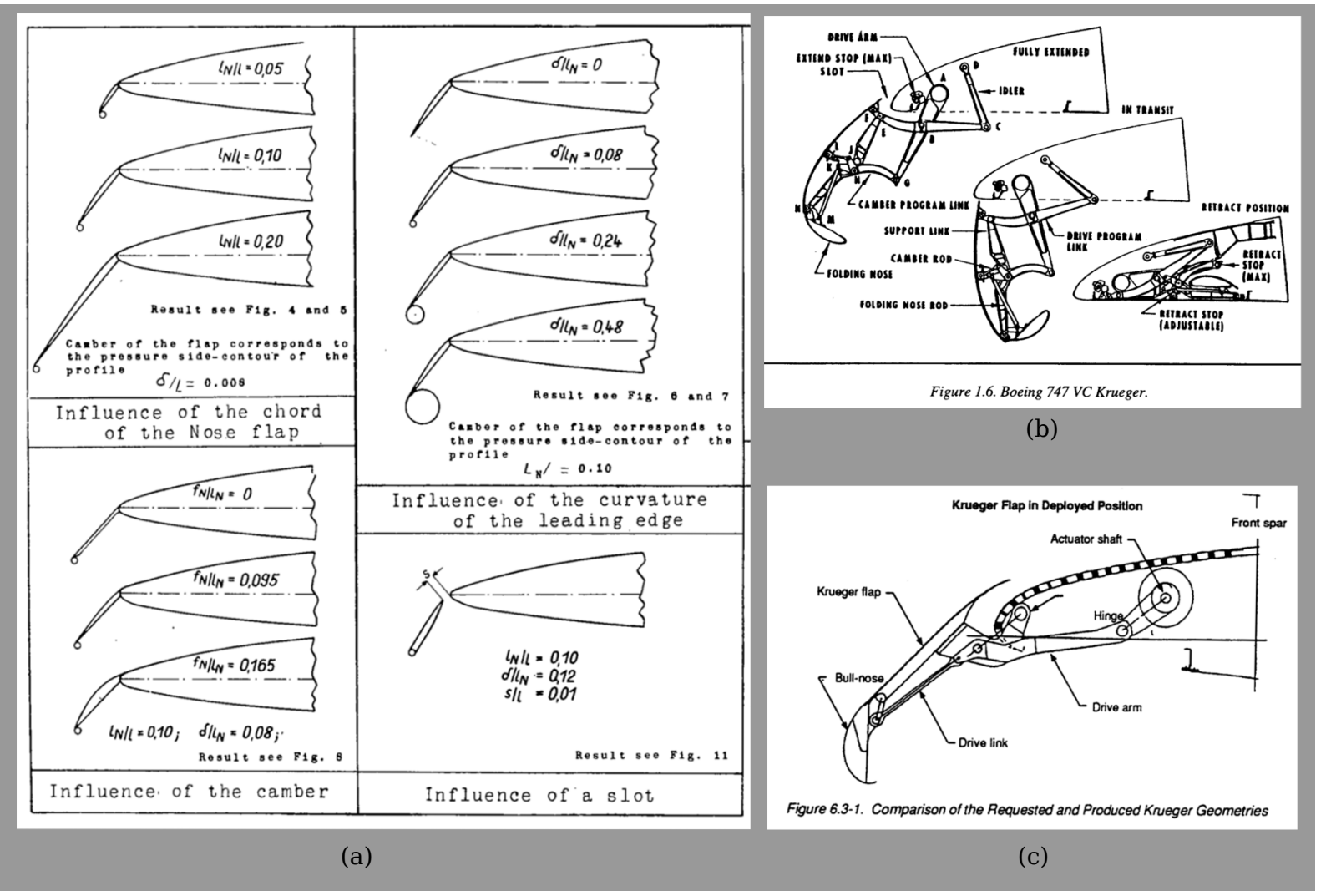

Figure 1. Evolution of Krueger flaps a) The original "nose-flap" designs by W. Krueger in $1947 .{ }^{6}$ Note the circular bull-nose and the slot (gap) present even in these earliest designs. b) A variable camber Krueger flap with a four-bar link deployment mechanism. This system was used along the entire leading edge of Boeing 747 introduced in $1970 .{ }^{1} \mathrm{c}$ ) The Krueger flap tested in Hybrid Laminar Flow Control (HLFC) Experiment by Boeing circa $1999 .{ }^{4}$ The flap does not have a variable camber but it can be deployed to separate positions for take-off and landing. Note the suction channels on top surface of the main wing near the leading edge for laminar flow control.

mechanism to provide a variable camber (Figure 1(b)). However, that level of complexity on a leading edge device was soon deemed too costly to manufacture and maintain, and Boeing abandoned use of Krueger flaps on its later airliners. ${ }^{1,5}$ After the $70 \mathrm{~s}$, most of the attention of the major aircraft manufacturers focused instead on leading edge slats, which benefited greatly from the increasing use of computational tools and resources in their design and optimization. Krueger flaps, on the other hand, were left mostly unimproved. ${ }^{7}$

Several notable reports involving the aerodynamic design and analysis of Krueger flaps were published since the late ' 70 s to date. ${ }^{4,8-18}$ To the authors' knowledge, only three of these publications demonstrate a systematic effort towards designing Krueger flaps. ${ }^{4,16,17}$ The noise characteristics of Krueger flaps are discussed only in the more recent ones. ${ }^{14,18}$

In 2009, NASA created the Environmentally Responsible Aviation (ERA) project to explore benefits and feasibility of novel fixed wing vehicle concepts and technologies to reduce the environmental impact of aviation. These technologies are expected to enter commercial service as early as 2025 and provide significant and specific reductions in fuel consumption, noise levels and nitrous oxide emissions relative to the vehicles in service today.

One of the air vehicle concepts evaluated within the ERA project is the Blended Wing Body (BWB) or the Hybrid Wing Body (HWB) concept, which is a commercial air transport vehicle concept with a highly integrated wing, fuselage and propulsion system to reduce fuel consumption and noise levels. A particular example of the HWB concept is presented by Guo et al. ${ }^{19}$ Another concept studied within the ERA project is a more familiar, tube-and-wing aircraft with engines positioned over the wing and near the fuselage to reduce noise levels on the ground..$^{20}$ Both air vehicles utilize laminar flow control technologies to reduce drag; therefore, a Krueger flap could be an appropriate leading edge device for these vehicles. In addition, with significant reduction of engine noise levels through shielding by the aircraft fuselage, the high-lift systems may become a more dominant noise source, especially during approach and landing when the engines are near 
idle condition. ${ }^{13,14}$ Hence, the potential aerodynamic and aeroacoustic benefits of Krueger flaps deserves further study.

The work presented in this paper started in late 2014 as a collaboration between the authors at NASA Ames Research Center (ARC) and NASA Langley Research Center (LaRC) to better understand the aeroacoustic behavior of Krueger flaps in relation to conventional slats, which have received significant attention in terms of noise source modeling. ${ }^{19,20}$ The effort focused on fundamental studies of $2 \mathrm{D}$ aeroacoustic behavior, with possible future work incorporating 3D effects. The ARC authors were mainly responsible for the design and simulation of the Krueger flap, while the LaRC authors were responsible for fabricating and testing both conventional slat and Krueger flap models. Details of the wind tunnel test campaign and its results are provided in a companion paper by Bahr et al. ${ }^{21}$ Another companion paper by Housman \& Kiris ${ }^{22}$ reports the computational aeroacoustic characterization of the conventional slat high-lift system.

The ultimate goal in this work is to design a high-lift system with a Kruger flap that creates the same amount of local lift force as the well-studied 30P30N high-lift system while both systems are installed into the QFF (Quiet Flow Facility) wind tunnel. Finding a Krueger flap configuration that has a higher lift, lower drag or any better aerodynamic performance metric was not particularly aimed. Local lift force here is defined as the lift generated by the leading edge device plus the lift generated by the leading edge region of the main element (i.e., from the leading edge until the $25 \%$-chord location of the stowed (cruise) wing). The particular 30P30N geometry used in this work had a slight modification in the slat cove region ${ }^{23}$ and was scaled down to a stowed wing chord of $0.425 \mathrm{~m}$ to reduce the turning effect of the model on the open-jet test section of the wind tunnel.

\section{Methods}

\section{II.A. Design and Selection of Krueger Flap Geometries}

The design study began with creating a set of parameters that defines the geometry (i.e. shape, position and orientation) of a 2D Krueger flap with a bull-nose, as well as its stowage cavity inside the main element. The set consists of 13 parameters shown in Figure 2: $l$ (length of the Krueger flap), $\Delta x_{\text {cut }}$ (x-distance of the upstream end of the stowage cavity from the leading edge of the main element), $h_{1}$ (depth of cavity at its upstream end), $h_{2}$ (depth of cavity at its downstream end), $h_{3}$ (thickness of the trailing edge of the Krueger flap), $h_{4}$ (thickness of the neck of the Krueger flap), $\Delta x$ (x-distance of the lower corner of the trailing edge of the Krueger flap from the leading edge of the stowed wing), $\Delta y$ (y-distance of the lower corner of the trailing edge of the Krueger flap from the leading edge of the stowed wing), $\theta_{1}$ (deployment angle of the Krueger flap), $\theta_{2}$ (turning angle of the bull-nose), $r$ (length of the bull-nose), and finally $a$ and $b$ (parameters that define the bull-nose shape). For comparison, the slat and the leading edge region of the 30P30N geometry used in this study are also shown in Figure 2. We designated 7 of the Krueger flap parameters, namely, $l, \Delta x_{\text {cut }}, \Delta x, \Delta y, \theta_{1}, \theta_{2}$ and $r$, as design variables while keeping the remaining Krueger flap parameters constant as $h_{1}=5.4 \mathrm{~mm}, h_{2}=14 \mathrm{~mm}, h_{3}=0.5 \mathrm{~mm}, h_{4}=4 \mathrm{~mm}, a=1.0$ and $b=0.8$. We defined the baseline Krueger flap to have $l=58 \mathrm{~mm}, \Delta x_{\text {cut }}=28 \mathrm{~mm}, \Delta x=-0.9 \mathrm{~mm}, \Delta y=0.0 \mathrm{~mm}, \theta_{1}=120^{\circ}$, $\theta_{2}=130^{\circ}$, and $r=6.5 \mathrm{~mm}$.

When selecting these 13 design parameters, we aimed to have only a few key parameters to define a Krueger flap with a bull-nose and a gap. When deciding on the value ranges of these design variables, our goal was to have a Krueger flap which is comparable in size to the slat, which requires a reasonably small stowage cavity inside the stowed wing, and complies with manufacturing, installation and load limits of the test setup. Finally, we determined the number of values to be considered for each design variable by considering the number of different cases we could evaluate within the computational resources and time allocated for this study. We conducted the design and selection process in three stages, as diagrammed in Figure 3:

1. Explore the impact of a subset of the variables at a few angles of attack: Change the cut-out length $(l)$, deployment position $(\Delta x, \Delta z)$ and deployment angle $\left(\theta_{1}\right)$ of the baseline design and carry out flow simulations for each variation in free-air at only two angles of attack $\alpha=2.2^{\circ}$ and $\alpha=4.5^{\circ *}$. Based on

${ }^{*}$ These angles of attack $\left(2.2^{\circ}\right.$ and $\left.4.5^{\circ}\right)$ were selected because they produce local $C_{\mathrm{p}}$ distributions comparable to the two tunnel installation angles of attack $\left(\alpha=27^{\circ}\right.$ and $\alpha=33^{\circ}$, respectively). Due to its relatively large size as compared to the cross-section of the open jet, the model would deflect the jet enough to decrease the effective angle of attack significantly and to make the operation of the facility unsafe. In order to match local $C_{\mathrm{p}}$ distributions with free-air cases while limiting the jet 
(a)

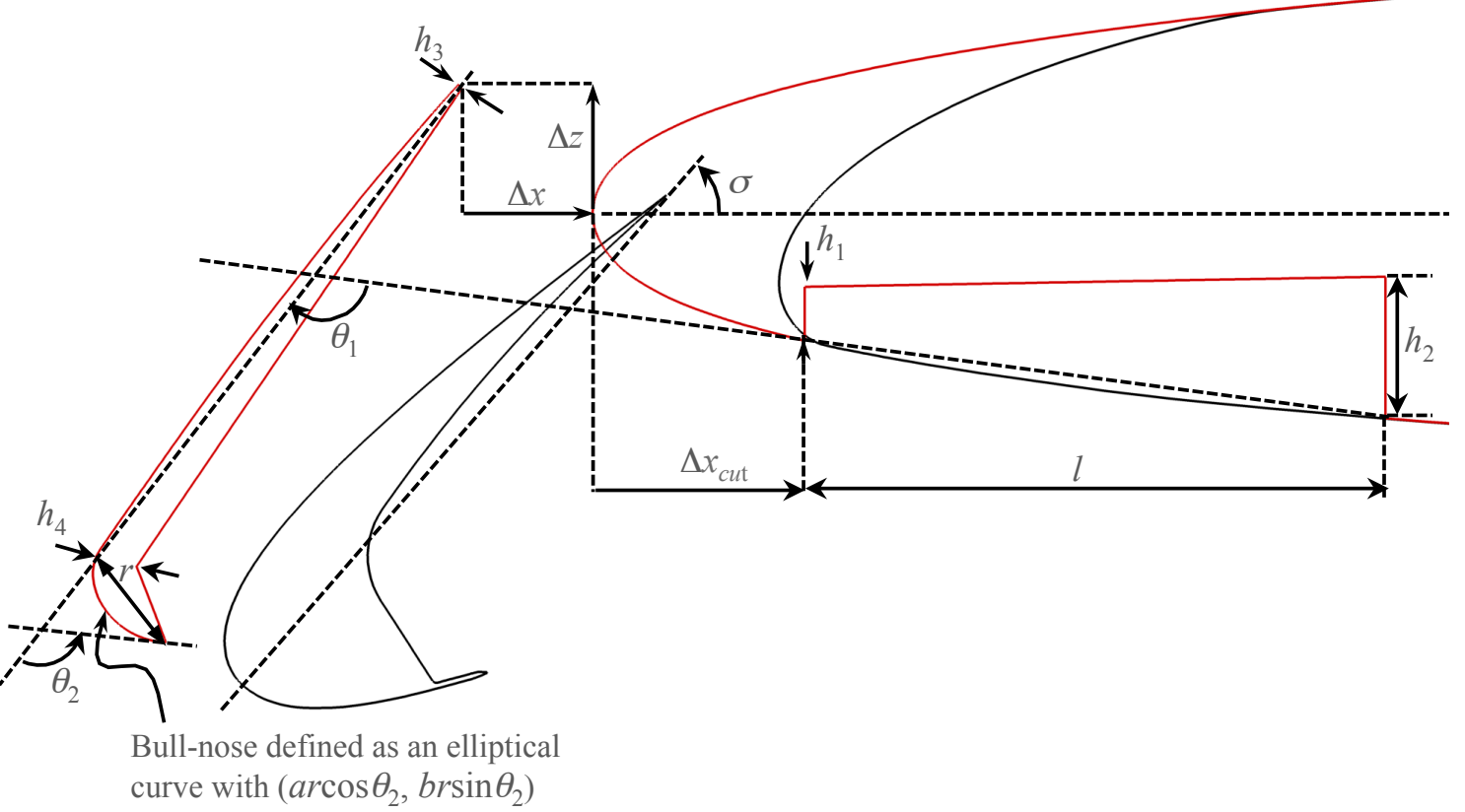

(b)

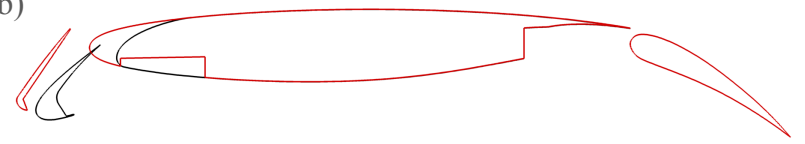

Flap deployed for free-air simulations

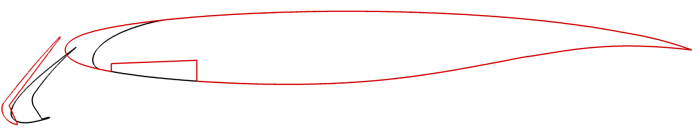

Flap stowed for in-tunnel simulations

Figure 2. a) Parameters defining the Krueger flap and stowage cavity. The high-lift system with the Krueger flap is shown in red whereas the system with the conventional slat is in black. b) The deployed flap and stowed flap configurations used in free-air and in-tunnel simulations, respectively.

the results of these simulations, select the Krueger flap shape which, on average, produced the closest lift coefficient to the configurations with slat (with slat deployment angles $10^{\circ}, 20^{\circ}$ and $30^{\circ}$ ).

2. Focus on shape adjustments within a larger angle of attack range: Modify the cut-out length (l), cutout distance $\left(x_{c u t}\right)$, bull-nose length $(r)$, and bull-nose turning angle $\left(\theta_{2}\right)$ of the design selected in the previous stage and carry out free-air flow simulations at angles of attack ranging from $2^{\circ}$ to $19^{\circ}$ with $0.5^{\circ}$ increments. Select the shape which produces the closest lift coefficient to the configurations with slat over a larger angle of attack range.

3. Fine-tune the deployment angle for the system installed in the tunnel: Install the configuration with the selected Krueger flap design into the wind tunnel grid system and carry out the "in-tunnel" flow simulations. Limit the area of force integration to the leading edge element and the first quarter chord region of the stowed (cruise) wing to compute a local lift coefficients of the high-lift systems. For each slat deployment angle, adjust the position and orientation of the selected Krueger flap shape so that the local lift coefficient of the Krueger configuration becomes as close as possible to that with the corresponding slat configuration.

In essence, Stage 1 was an exploration of the design space with respect to the variables we thought had the most impact on the lift coefficient. Stage 2 was performed to explore the impact of shape modifications in a range of angle of attack that goes beyond $C_{1, \max }$. Finally, Stage 3 is performed to make any adjustments in position and orientation to compensate for wind tunnel effects. The wind tunnel simulations in Stage 3 are about 4.5 times more expensive than the free-air simulations in Stage 1 and 2; therefore, conducting a

flow turning, we had to install the model at such large angles and stow its flap. Further information on determination of these angles can be found in the companion paper by Bahr et al. ${ }^{21}$ and in Mendoza et al. ${ }^{24}$ 
Stage 1: Full factorial combinations of the following variations simulated at $\alpha=2.2^{\circ}$ and $4.5^{\circ}$.

A total of 1260 steady-state, 2D, free-air flow simulations. Flap deployed.

Krueger flap length:

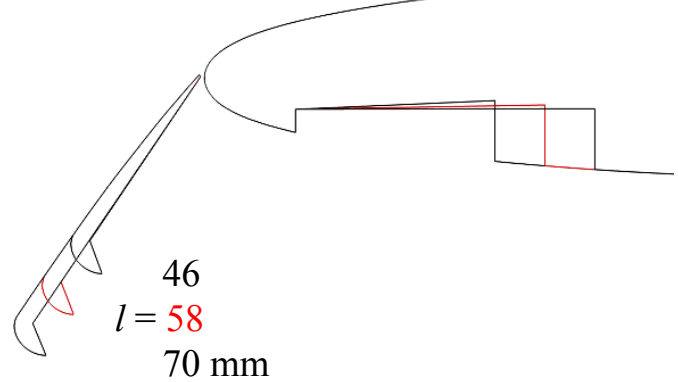

Translations:

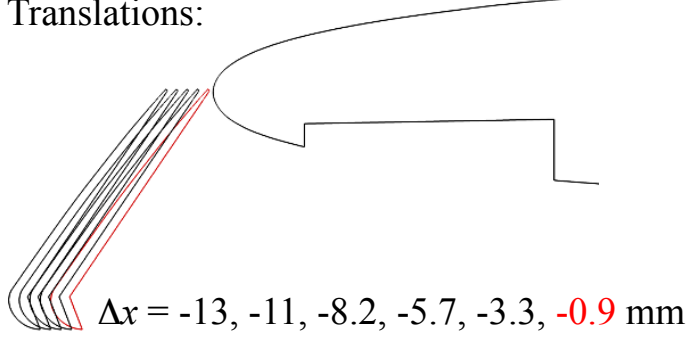

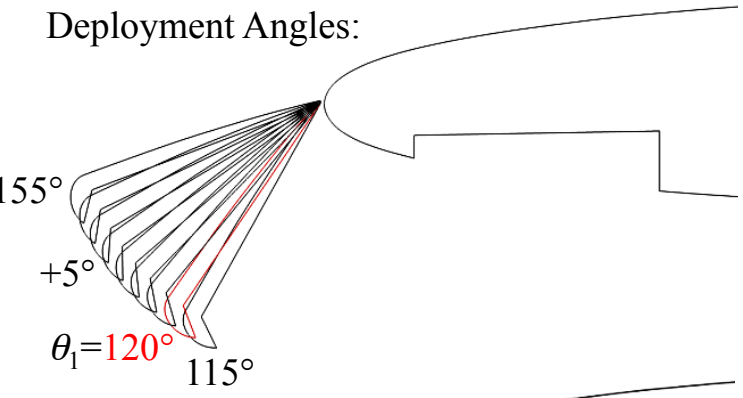

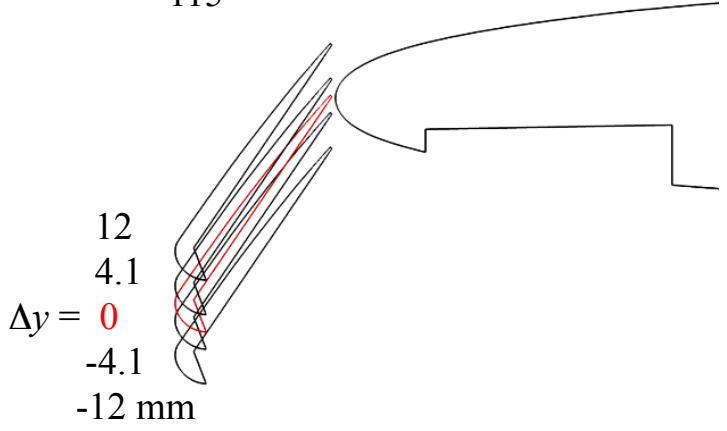

Stage 2: Variations of the baseline Krueger configuration simulated at angles from $\alpha=2^{\circ}$ to $19.5^{\circ}$ with $0.5^{\circ}$ increments. A total of 945 steady state, $2 \mathrm{D}$, free-air flow simulations. Flap deployed.

Bull-nose length

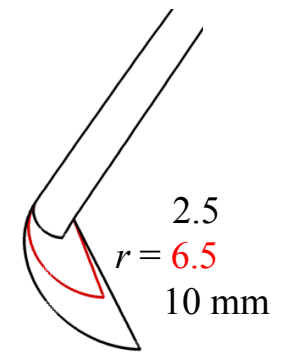

Bull-nose turning angle

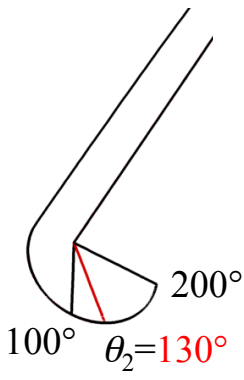

Cut-out distance

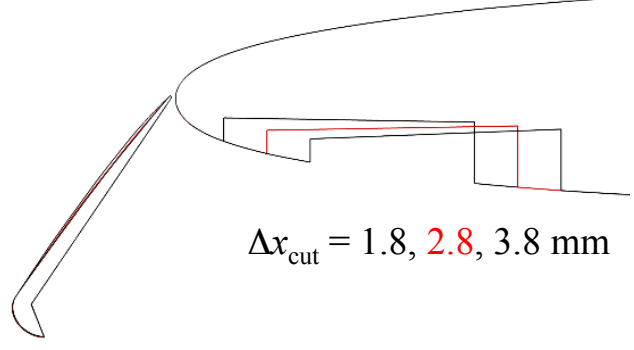

Stage 3: Fine-tuning deployment angle and translations for different slat angles.

A total of 208 unsteady, 2D, in-tunnel flow simulations. Flap stowed.

Tuned for $\sigma=10^{\circ}$

at $\alpha=27^{\circ}$

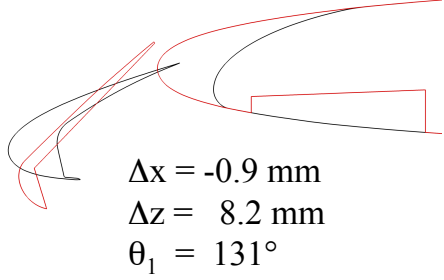

$\alpha=33^{\circ}$

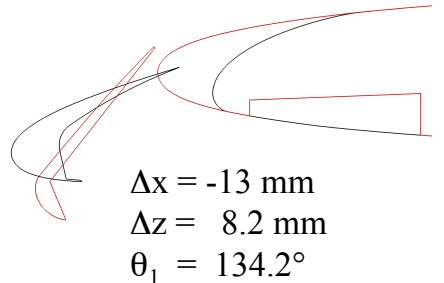

$\sigma=20^{\circ}$
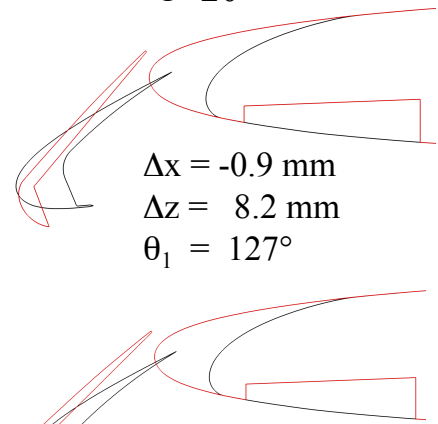

$\Delta \mathrm{x}=-13 \mathrm{~mm}$

$\Delta \mathrm{z}=8.2 \mathrm{~mm}$

$\theta_{1}=132.2^{\circ}$

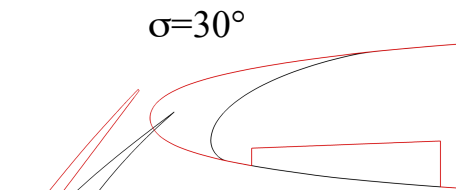

$\Delta \mathrm{x}=-3.3 \mathrm{~mm}$

$\Delta \mathrm{z}=8.2 \mathrm{~mm}$

$\theta_{1}=124^{\circ}$

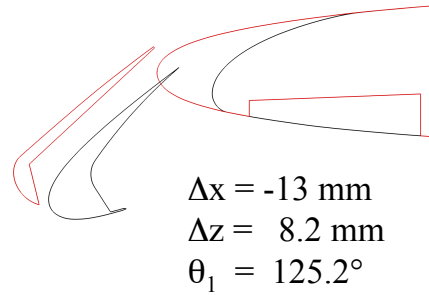

Figure 3. The three stages of the Krueger flap design for the test campaign. The baseline Krueger flap configuration shape and values are shown in red in Stage 1 and 2. In Stage 3, the selected high-lift system with the Krueger flap is shown in red whereas the corresponding system with the conventional slat is shown in black. 
majority of the design space exploration through free-air simulations in Stage 1 and 2 saved a significant amount of computational resources.

\section{II.B. Computational Methods}

The computational fluid dynamics (CFD) analyses in this work were carried out using the structured overset solver capability of the Launch, Ascent and Vehicle Aerodynamics (LAVA) framework developed at NASA Ames Research Center. ${ }^{25}$

The free-air simulations in this study are 2D, steady Reynolds averaged Navier Stokes (RANS) flow solutions with freestream conditions set to $M_{\infty}=0.17$ and $R e_{\infty}=1.7 \times 10^{6}$ (based on the stowed-wing chord length of $c=0.425 \mathrm{~m}$ ), which are the same conditions as for the wind tunnel tests. In their companion paper, Housman \& Kiris $^{22}$ investigated the time-dependent, three-dimensional effects through a set of 3D, unsteady flow simulations with the 30P30N high-lift system installed in this particular wind tunnel. They found out that at certain installation and slat deployment angles, bistable separation bubbles appear where either end of the model meets the wind tunnel walls. However, they concluded that 2D unsteady RANS simulations were able to predict the $C_{\mathrm{p}}$ distribution at the mid-span of the model with sufficient accuracy. In light of that conclusion we carried out 2D unsteady RANS simulations for all of the in-tunnel cases in this study.
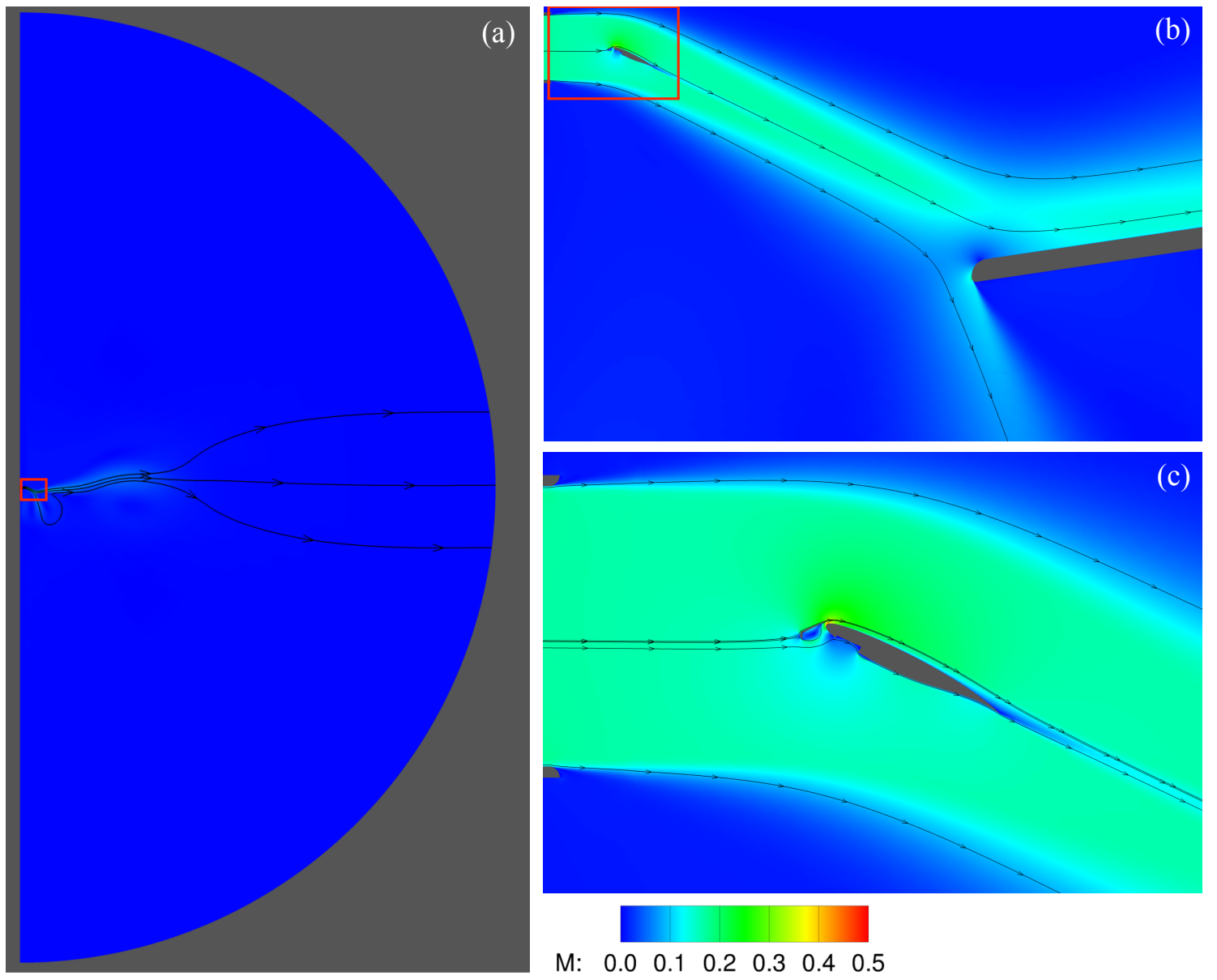

Figure 4. The flow domain for in-tunnel simulations: a) The view of the entire semi-circular domain, b) and c) successive close-up into the red squares. The colormap is of the Mach number; a few streamlines are also shown. A large portion of the jet collector plate deflecting the flow is visible in $b$ ).

The simulations required generation of the Krueger flap geometry as well as the structured overset grid system around the high-lift system. For the free-air simulations, we generated a circular grid system that extends around 400 chord lengths away from the high-lift system. For the wind-tunnel simulations, however, we generated a grid system that represents the mid-span cross section of the wind tunnel plus a large, semicircular expansion domain that extends about 385 chord lengths (265 tunnel widths) around the exit of the 
wind tunnel opening (Figure 4). Therefore, the simulated geometry of the facility test section included the tunnel and exhaust jet collector plate (Figure $4 \mathrm{~b}$ ) but not the walls of QFF anechoic chamber, which are more than 3 meters away from the experimental setup.

The free-air grid system had around 1.2 million vertices while the in-tunnel grid system had around 3.5 million vertices. Both grid systems had a normalized wall distance $\left(y^{+}\right)$of 1.5 which was confirmed after the flow solutions. Generation of the grid systems and creation of the Krueger flap geometry were accomplished using Chimera Grid Tools (CGT), which is a NASA-developed toolset to generate structured, body-fitted, overset grid systems in a scripted way. ${ }^{26,27}$ The overset grid connectivity was performed with a new, automated grid connectivity tool ${ }^{22}$ with triple fringe grid overlap and a minimum donor quality factor ${ }^{28}$ of 0.9. Once the overset grid connectivity was completed, the angle of attack was set simply by adjusting the velocity components of the freestream for the free-air simulations. For the wind tunnel simulations, however, the near body grids needed to be rotated with respect to the wind tunnel grids by the angle of attack desired. This required performing overset grid connectivity for each angle of attack considered for a given configuration in the wind tunnel. Use of the automated connectivity tool was an important time saving element in this computational work.

The flow solver used in this work solved the RANS equations in strong conservation law form for a non-orthogonal curvilinear coordinate system. The convective fluxes were computed with a hybrid, sixthorder accurate weighed compact nonlinear (WCNO) scheme using a modified Roe scheme for numerical fluxes. Viscous fluxes were computed with a standard second order accurate central scheme. For the freeair simulations, the solver was run in steady-state mode with local pseudo-timestepping using a CourantFriedrics-Lewy (CFL) number of 10. For the in-tunnel simulations it was run in unsteady-mode with a second-order backward differencing in time with steps of $\Delta t=0.5 \times 10^{-3} \mathrm{~s}$ and 10 sub-iterations per time step with a CFL number of 10 for a total of 10,000 time-steps. Simulation results reported in this paper are based on the average of the last 2000 time steps, which start after about 35 freestream convection times from the exhaust plane of the tunnel to the end of the collector plate (approximately $6.5 \mathrm{~m}$ ). This ensured that the transient flow features in the beginning of the solution disappear before the averaging starts.

Both the free-air and in-tunnel simulations had 5 grid points along the spanwise direction of the flow domain. Faces covering either side of the domain in the spanwise direction were given symmetry boundary condition, which makes the solution at the mid-plane effectively a 2D solution. All the solid surfaces were given an adiabatic, no-slip wall boundary condition. For the free-air simulations, a standard inflow/outflow boundary condition was applied on all the other domain boundaries. For the in-tunnel simulations, all the remaining domain boundaries (except for the inlet of the tunnel) had a pressure boundary condition that fixed the static pressure while extrapolating all the other flow field variables. At the inlet of the tunnel, the stagnation pressure and temperature were fixed to values that produce a Mach number of $M=0.17$ at the exhaust plane of the tunnel contraction.

Both the free-air and the in-tunnel simulations utilized Spalart-Allmaras (SA) turbulence model. Further details on the solution methodology can be found in Housman \& Kiris $^{22}$ and Kiris et al. ${ }^{25}$

Simulation of each free-air case took about 4 hours to converge on one Ivybridge node (20 cores) of the Pleiades supercomputer at NASA Ames Research Center. Each in-tunnel simulation required about 6 hours on three Ivybridge nodes (60 cores), making an in-tunnel simulation about 4.5 times more computationally expensive than a free-air simulation.

\section{Results and Discussion}

Results of each design stage are presented and discussed as follows:

Stage 1: An analysis of the Stage 1 results indicated that there is more than one Krueger flap design that can match the lift coefficient of a corresponding slat configuration with a difference less than $1 \%$. These designs had either the baseline length or the shorter Krueger flap - the longer Krueger flap created less lift and more drag by up to $8 \%$ difference. In general, the candidate Krueger flaps were those that we placed relatively close to the leading edge $(\Delta x, \Delta z<8 \mathrm{~mm}$ or $2 \%$ of the chord) and deployed at angles varying from $150^{\circ}$ to $120^{\circ}$, depending on the corresponding slat deployment angle $\left(10^{\circ}, 20^{\circ}\right.$ or $\left.30^{\circ}\right)$ targeted. With a few additional simulations at higher angles of attack, we found out that configurations with relatively large deployment angles create drastically less lift than those with smaller deployment angles. Based on these findings, we decided to investigate variations of the $C_{1}$ vs. $\alpha$ curve while targeting only the slat deployment angle of $\sigma=30^{\circ}$. 
Stage 2: The lift curves of the variations investigated in this stage are shown in Figure 5. Figure 5(a) and (b) shows that the effects of cut-out location for the Krueger flap $\left(x_{c u t}\right)$ and turning angle of the bull-nose $\left(\theta_{2}\right)$ on the lift curve are negligible. Increasing the length of the Krueger flap had an overall effect of tilting the lift curve counterclockwise around the midrange, thereby reducing the lift coefficient when $\alpha<10^{\circ}$ and increasing it when $\alpha>10^{\circ}$ (Figure 5(c)). Contrary to our presumption in Stage 1, however, we found out that the length of the bull-nose had the highest impact on the entire lift curve as shown in Figure5(d). Increasing the length of the bull-nose by about $50 \%$ almost completely eliminated stall while causing a small decrease in lift at installation angles of attack less than $\alpha<10^{\circ}$. We thus selected the Krueger flap with the longer bull-nose to proceed with in Stage 3.

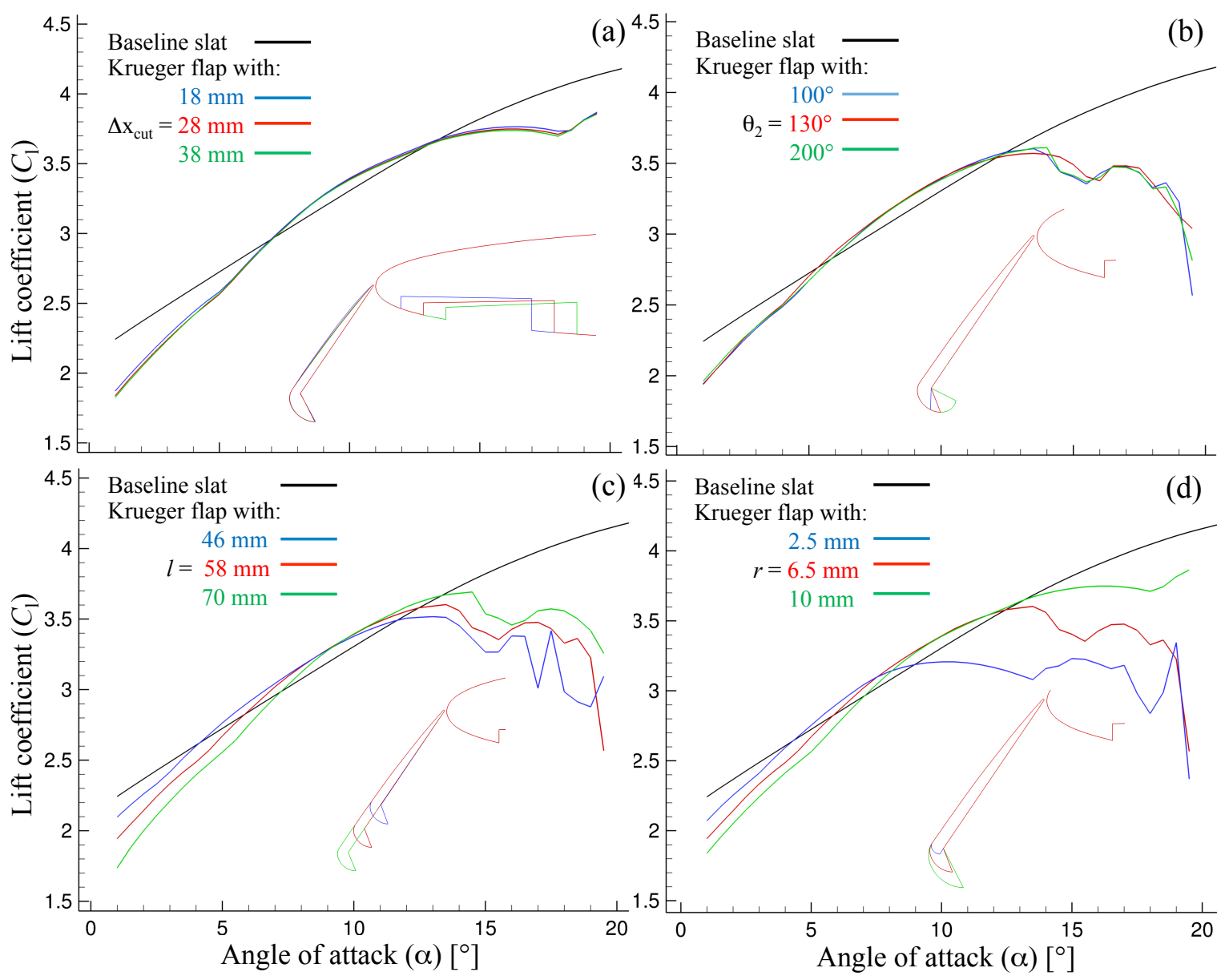

Figure 5. Lift curves of the high-lift system with Krueger flap variations around the baseline design. a) Cut-out distance variations b) bull-nose turning angle variations c) Krueger flap length variations d) bull-nose length variations.

Stage 3: In this stage, we adjusted the position and deployment angle of the Krueger flap selected in Stage 2 to match it more precisely to each corresponding slat configuration installed in the tunnel at $\alpha=27^{\circ}$ and $\alpha=33^{\circ}$. The goal in this stage was to match the local lift coefficient of the high-lift systems, therefore we limited the force integration to the leading edge element and the leading edge region of the main element until the $25 \%$ chord location of the stowed wing.

We conducted Stage 3 in a few iterations. In each iteration, we eliminated another variable and tuned the remaining one(s) more precisely to find a better match of the local lift coefficients. In the first iteration, we simulated the full factorial combinations of $\Delta x=-0.9,-3.3,-8.2,-13 \mathrm{~mm}, \Delta z=-8.2,0.0,8.2 \mathrm{~mm}$, at several angles varying from $\theta_{1}=111^{\circ}$ to $131^{\circ}$. We noted that only the combinations of $\Delta x=-0.9,-3.3$ $\mathrm{mm}$ and $\Delta z=0.0,8.1 \mathrm{~mm}$ produced enough local lift to match the configurations with slat.

In the second iteration, we found out that $\Delta x=-0.9 \mathrm{~mm}$ is a suitable value for all slat deployment angles, except for $\sigma=30^{\circ}$ at $\alpha=27^{\circ}$, which required $\Delta x=-3.3 \mathrm{~mm}$. We also found out that applying a moderate upward shift of $\Delta z=8.2 \mathrm{~mm}$ to the Krueger flap also improved the match of local lift values. 
Table 1. Final position and orientation of the selected Krueger flap shape.

\begin{tabular}{|c|c|c|c|c|c|c|}
\hline \multirow[b]{2}{*}{ For slat deployment angle: } & \multicolumn{3}{|c|}{ at $\alpha=27^{\circ}$} & \multicolumn{3}{|c|}{ at $\alpha=33^{\circ}$} \\
\hline & $\sigma=10^{\circ}$ & $\sigma=20^{\circ}$ & $\sigma=30^{\circ}$ & $\sigma=10^{\circ}$ & $\sigma=20^{\circ}$ & $\sigma=30^{\circ}$ \\
\hline$\Delta x[\mathrm{~mm}]$ & -0.0009 & -0.0009 & -0.0033 & -0.0009 & -0.0009 & -0.0009 \\
\hline$\Delta z[\mathrm{~mm}]$ & 0.0082 & 0.0082 & 0.0082 & 0.0082 & 0.0082 & 0.0082 \\
\hline$\theta_{1}\left[^{\circ}\right]$ & 131.0 & 127.0 & 124.0 & 134.2 & 132.2 & 125.2 \\
\hline$C_{\text {l,local }}$ with slat & 0.747 & 0.713 & 0.686 & 0.949 & 0.912 & 0.877 \\
\hline$C_{\text {l,local }}$ with Krueger flap & 0.750 & 0.713 & 0.689 & 0.958 & 0.923 & 0.906 \\
\hline$C_{\mathrm{d} \text {,local }}$ with slat & 0.0711 & 0.0599 & 0.0494 & 0.117 & 0.102 & 0.0883 \\
\hline$C_{\mathrm{d} \text {,local }}$ with Krueger flap & 0.0484 & 0.0472 & 0.0430 & 0.0951 & 0.0952 & 0.0843 \\
\hline with slat & 1.21 & 1.19 & 1.18 & 1.45 & 1.42 & 1.40 \\
\hline with Krueger flap & 1.19 & 1.14 & 1.12 & 1.45 & 1.40 & 1.39 \\
\hline with slat & 0.312 & 0.307 & 0.305 & 0.441 & 0.434 & 0.427 \\
\hline with Krueger flap & 0.302 & 0.293 & 0.291 & 0.436 & 0.430 & 0.422 \\
\hline
\end{tabular}

In the third and final iteration, we fine-tuned the deployment angles and established the final Krueger flap configurations for each slat configuration and at both angles of attack. These configurations, along with the local and total lift and drag coefficients they produce, are listed in Table 1. Note that the drag coefficient of the Krueger flap configuration is consistently lower than that of the corresponding slat configuration, although this was not a particular design goal. Streamlines, pressure coefficient $\left(C_{\mathrm{p}}\right)$ contours and Mach number $(M)$ contours around two in-tunnel configurations (slat configuration with $\sigma=30^{\circ}$ and the corresponding Krueger flap configuration) at $\alpha=27^{\circ}$ are shown in Figure 6. The Krueger flap has a larger recirculation zone behind it as compared to the slat. In addition, the configuration with the Krueger flap has a more pronounced flow acceleration through the gap and a more prevalent deceleration on the lower upstream part of the main element due to scooping of air by the cavity.

Pressure coefficients on the surface of the high-lift systems are plotted in Figure 7 and, for $\sigma=30^{\circ}$ configuration, validated with available experimental data. The peak suction amplitude around the leading edge of the main element with the Krueger flap is significantly larger than the peak that occurs with the corresponding slat. This strong suction region creates a remarkable amount of additional lift force because it acts on an extra main wing area that the slat configuration does not have. However, these contributions to the lift force of the Krueger flap configuration are largely offset by the loss of suction over the remaining part of the top surface and loss of pressure over the cavity region of the bottom surface of the main element. As a result, these Krueger flap configurations produce approximately the same amount of lift as the slat configuration (0.689 vs 0.686 ) over the first quarter of the full-wing chord.

\section{Summary}

Krueger flaps regained research interest over the past several years due to their potential in enabling laminar flow technology, but their use requires additional study of the Krueger flap impact on airframe noise. The purpose of this work was to design a test article that can be used in a series of comparative wind tunnel tests to study aeroacoustic noise generation mechanisms around Krueger flaps and conventional slats under similar aerodynamic lift conditions. We thus designed a high-lift system in free air with a Kruegerflap that matched the lift of a system with conventional slat using the same cruise airfoil profile. In order to do this, we derived a set of parameters that define the shape, position and orientation of a Krueger flap with respect to the stowed (cruise) wing. Based on more than 2,000 steady, 2D RANS simulations on many variations of the design in free air, we chose one Krueger flap shape to be built for wind tunnel tests. We then adjusted the position of the Krueger flap to match the lift force generated by the leading edge region of these high-lift systems when installed in the NASA LaRC QFF open-jet testing facility. We observed that the high-lift systems with the Krueger flap exhibited a more pronounced flow acceleration in the gap region and deceleration around the cavity region as compared to the system with a conventional slat, 

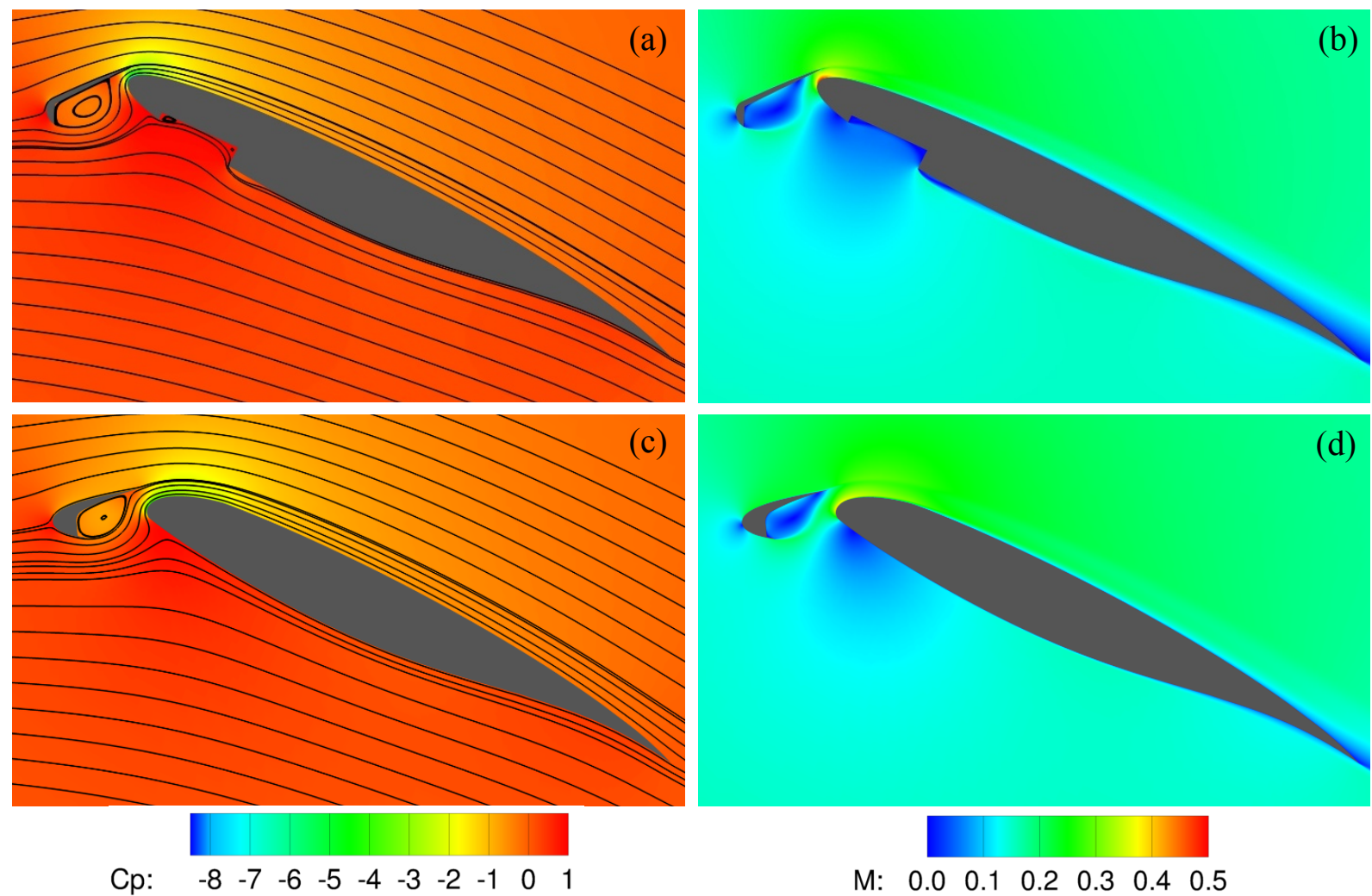

Figure 6. Streamlines, contours of pressure coefficient $\left(C_{\mathbf{p}}\right)$ and of Mach number ( $\left.M\right)$ around two in-tunnel configurations at $\alpha=27^{\circ}$ : (a) and (b) for the Krueger flap configuration, (c) and (d) for the corresponding slat configuration with $\sigma=30^{\circ}$.

although the lift forces generated over the first quarter-chord portion of the two systems are nearly the same. The simulations predicted the surface pressure coefficients very well over most of the surfaces, providing confidence in carrying out further analysis of these cases using our computational tools. We anticipate that results from further experimental and computational analyses of these test articles will provide insights on aeroacoustic characteristics of the two high-lift systems. Based on these insights we can perform a rigorous design and optimization study to find an aerodynamically and aeroacoustically better Krueger flap.

\section{Acknowledgements}

We would like to acknowledge funding from NASA Environmentally Responsible Aviation (ERA) Project and technical contributions from Shayan Moini-Yekta from ARC, Casey L. Burley and Russell H. Thomas from LaRC, and Yueping Guo from NEAT Consulting. Computing resources were provided by NASA Advanced Supercomputing (NAS) Division at NASA Ames Research Center.

\section{References}

${ }^{1}$ Rudolph, P. K. C., "High-Lift systems on Commercial Subsonic Airliners," Contractor Report 4746, NASA, 1996.

${ }^{2}$ Tamigniaux, T. L. B., Stark, S. E., and Brune, G. W., "An Experimental Investigation of the Insect Shielding Effectiveness of a Krueger Flap/Wing Airfoil Configuration," 5th Applied Aerodynamics Conference, 1987, AIAA-1987-2615.

${ }^{3}$ Wicke, K., Linke, F., and Gollnick, V., "Insect Contamination Impact on Operational and Economic Effectiveness of Natural-Laminar-Flow Aircraft," Journal of Aircraft, Vol. 0, 2015, pp. 1-10, Early access, DOI: 10.2514/1.C033237.

${ }^{4}$ Boeing Commercial Airplane Group, Seattle, Washington, "High Reynolds Number Hybrid Laminar Flow Control (HLFC) Flight Experiment II. Aerodynamic Design," Contractor Report CR-1999-209324, NASA, 1999.

${ }^{5}$ van Dam, C. P., "The Aerodynamic Design of Multi-element High-lift Systems for Transport Airplanes," Progress in Aerospace Sciences, Vol. 38, 2002, pp. 101-144.

${ }^{6}$ Krueger, W., "Systematic Wind-Tunnel Measurements on a Laminar Wing with Nose Flap," Technical Memorandum 1119, NASA, 1947.

${ }^{7}$ Antunes, A. P., da Silva, R. G., and Azevedo, J. L. F., "A Study of Transport Aircraft High-Lift Design Approaches," 45th AIAA Aerospace Sciences Meeting and Exhibit, January 2007, AIAA-2007-38. 

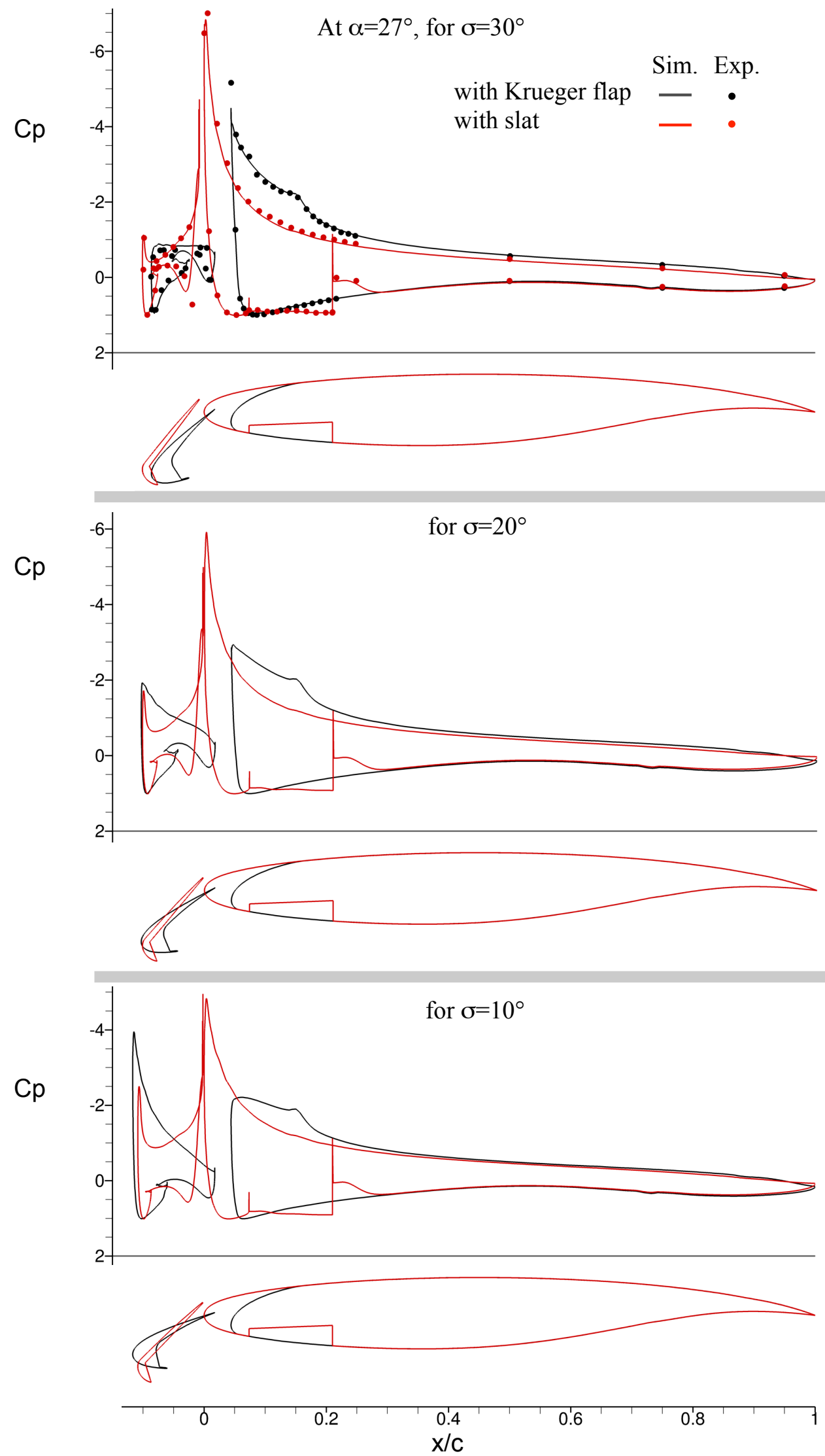

Figure 7. Pressure coefficients on the surface of the test articles. $C_{p}$ data and airfoil shape are printed in red for Krueger flap configuration and in black for conventional slat configuration. Experimental data is available only for the $\sigma=30^{\circ}$ case. For details on the experimental data, please see the companion paper by Bahr et al. ${ }^{21}$

\section{1 of 12}


${ }^{8}$ Williams, A. L., "A New and Less Complex Alternative to the Handley Page Slat," Journal of Aircraft, Vol. 23, 1986, pp. 200-206.

${ }^{9}$ Edi, P. and Fielding, J. P., "Civil-Transport Wing Design Concept Exploiting New Technologies," Journal of Aircraft, Vol. 43, No. 4, 2006, pp. 932-940.

${ }^{10}$ Fox, S. J. and Sakurai, S., "Link mechanisms for gapped rigid Krueger flaps, and associated systems and methods," US Patent, 82009.

${ }^{11}$ Jirasek, A. and Amoignon, O., "Design of a High-Lift System with Droop Nose Device," Journal of Aircraft, Vol. 23, 1986, pp. 200-206.

${ }^{12}$ Moraris, V. M., Lawson, N. J., and Gary, K. P., "Aerodynamic and performance Characteristics of a Passive Leading Edge Krueger Flap at Low Reynolds Numbers," The Aeronautical Journal, Vol. 116, 2012, pp. 759-769.

${ }^{13}$ Yao, H., Davidson, L., Erikson, L.-E., Eliasson, P., Grundestam, O., and Peng, S.-H., "Aeroacoustic Asessement of Conceptual Low-Noise High-Lift Wing Configurations," 50th AIAA Aerospace Sciences Meeting, January 2012, AIAA-20120383.

${ }^{14}$ Eliasson, P., Grundestam, O., Peng, S.-H., Yao, H., Davidson, L., and Erikson, L.-E., "Assessment of High-lift Concepts for a Regional Aircraft in the ALONOCO Project," 50th AIAA Aerospace Sciences Meeting, January 2012, AIAA-2012-0277.

${ }^{15}$ Bright, M. M., Korntheuer, A., Komadina, S., and Lin, J. C., "Development of Advanced High Lift Leading Edge Technology for Laminar Flow Wings," 51st AIAA Aerospace Sciences Meeting, January 2013, AIAA-2013-0211.

${ }^{16}$ Iannelli, P., Wild, J., Minervino, M., Struber, H., Moens, F., and Vervliet, A., "Design of a High-Lift System for a Laminar Wing," 5th European Conference for Aeronautics and Space Sciences (EUCASS), 2013.

${ }^{17}$ ElDin, I. S., Godard, J. L., Rodde, A. M., Moens, F., and et al., G. A., "Natural Laminar Flow Transonic Wing Design Applied to Future Innovative Green Regional Aircraft," 3AF/ CEAS Conference "Greener Aviation: Clean Sky breakthroughs and worldwide status", Bruxelles, Belgium, March 2014, [Online; accessed 24-October-2015].

${ }^{18}$ Pott-Pollenske, M., Almoneit, D., and Wild, J., "On Noise Generation of Krueger Leading Edge Devices," AIAA Aviation Forum, June 2015, AIAA-2015-3142.

${ }^{19}$ Guo, Y., Burley, C. L., and Thomas, R. H., "On Noise Assessment for Blended Wing Body Aircraft," 52nd Aerospace Sciences Meeting, January 2014, AIAA-2014-0365.

${ }^{20}$ Guo, Y., Nickol, C. L., and Thomas, R. H., "A Study of Transport Aircraft High-Lift Design Approaches," 52nd Aerospace Sciences Meeting, January 2014, AIAA-2014-0257.

${ }^{21}$ Bahr, C. J., Hutcheson, F. V., Thomas, R. H., and Housman, J. A., "A Comparison of Noise Mechanisms for Conventional Slat and Krueger Flap Noise," 22nd AIAA/CEAS Aeroacoustics Conference, 2016.

${ }^{22}$ Housman, J. A. and Kiris, C., "Slat Noise Predictions using High-Order Finite-Difference Methods on Overset Grids," 22nd AIAA/CEAS Aeroacoustics Conference, 2016.

${ }^{23}$ Turner, T. L., Kidd, R. T., Hartl, D. J., and Scholten, W. D., "Development of a SMA-Based, Slat-Cove Filler for Reduction of Aeroacoustic Noise Associated with Transport-Class Aircraft Wings," Proceedings of the ASME 2013 Conference on Smart Materials, Adaptive Structures and Intelligent Systems, 2013.

${ }^{24}$ Mendoza, J., Brooks, T., and Humphreys, W. M., "Aeroacoustic Measurements of a Wing/Slat Model," 8th AIAA/CEAS Aeroacoustics Conference, Breckenridge, Colorado, June 2002, AIAA-2002-2604.

${ }^{25}$ Kiris, C. C., Barad, M. F., Housman, J. A., Sozer, E., Brehm, C., and Moini-Yekta, S., "The LAVA Computational Fluid Dynamics Solver," 52nd Aerospace Sciences Meeting, 2014, AIAA-2014-0070.

${ }^{26}$ Chan, W., Gomez, R., Rogers, S., and Buning, P., "Best Practices in Overset Grid Generation," 32nd AIAA Fluid Dynamics Conference and Exhibit, St. Louis, Missouri, Jun 24-26 2002, AIAA-2002-3191.

${ }^{27}$ Chan, W., "Developments in Strategies and Software Tools for Overset Structured Grid Generation and Connectivity," 20th AIAA Computational Fluid Dynamics Conference and Exhibit, Honolulu, Hawai, Jun 27-30 2011, AIAA-2011-3051.

${ }^{28}$ Chiu, I. T. and Meakin, R., "On Automating Domain Connectivity for Overset Grids," 33rd Aerospace Sciences Meeting and Exhibit, January 9 -12 1995, Reno, NV. 